\title{
Fluoride Adsorption onto Acid-Treated Diatomaceous Mineral from Kenya
}

\author{
Enos W. Wambu ${ }^{1,2}$, Charles O. Onindo ${ }^{1}$, Willis J. Ambusso ${ }^{3}$, Gerald K. Muthakia ${ }^{4}$ \\ ${ }^{1}$ Department of Chemistry, Kenyatta University, Nairobi, Kenya; ${ }^{2}$ Current Address: Department of Chemistry, Bondo University Co- \\ llege, Bondo, Kenya; ${ }^{3}$ Department of Physics, Kenyatta University, Nairobi, Kenya; ${ }^{4}$ Department of Chemistry, Kimathi University \\ College of Technology, Nyeri, Kenya. \\ Email: \{wambuenos, coonindo, wambusso,gkmuthakia\}@yahoo.com
}

Received May $11^{\text {th }}, 2011$; revised July $7^{\text {th }}, 2011$; accepted September $23^{\text {rd }}, 2011$.

\begin{abstract}
Adsorption of Fluoride (F) from aqueous solutions using acid treated diatomaceous earth (ATDE) from a mining site in Kenya was studied using batch experiments. The effect of $F$ concentration, adsorbent dosage, contact time, temperature, pH and competing anions was evaluated. The adsorption process was fast and an initial equilibrium could be attained in just 10 min. Fluoride adsorption onto ATDE increased strongly from about 40\% to over 92\% when the solution temperature was raised from 293 to $303 \mathrm{~K}$. The process was however, less responsive to pH changes dropping by a margin of less than $1 \%$ from $98.8 \%$ to $98 \%$ when the solution pH was raised from 1.59 to 6.89 . It was clear that increase in concentration of $\mathrm{OH}^{-}$ions did not affect $F$ adsorption onto ATDE strongly. On the other hand, apart from the $\mathrm{Cl}^{-}$ions which slightly reduced $\mathrm{F}$ adsorption onto ATDE, there was no obvious effect of the $\mathrm{SO}_{4}^{2-}, \mathrm{NO}_{3}^{-}$and $\mathrm{PO}_{4}^{3-} \quad$ ions on $\mathrm{F}$ uptake by ATDE. Complete F removal (100\% adsorption) could be achieved at $400 \mathrm{mg} / \mathrm{L}$ initial $\mathrm{F}$ concentrations using $0.5 \mathrm{~g} / \mathrm{mL}$ ATDE batch loading, $303-313 \mathrm{~K}$ and $\mathrm{pH}=3.4 \pm 0.2$. The F adsorption data correlated to the Freundlich and Langmuir models and could be classified as H-Type according to Giles classification of isotherms. The maximum Langmuir F adsorption capacity of ATDE was $51.1 \mathrm{mg} / \mathrm{g}$ indicating that the mineral could be used as an inexpensive adsorbent for the removal of $F$ ions from aqueous streams.
\end{abstract}

Keywords: Acid Activated Diatomaceous Earth, Competing Anions, Fluoride Adsorption Isotherms

\section{Introduction}

At permissible levels, fluoride (F) is essential and desired for development and maintenance of strong bones and teeth $[1,2]$. At higher levels, however, prolonged fluoride exposure leads to dental and skeletal fluorosis and in severe cases to neurological and kidney disorders [3]. The primary cause of excessive human exposure to $\mathrm{F}$ is drinking high $\mathrm{F}$ water when alternative low $\mathrm{F}$ domestic water is not accessible. Countries along the Eastern Africa Rift Valley are among regions in the world where high $\mathrm{F}$ water and endemic fluorosis has been reported [4,5]. Excess fluoride in water sources in these regions results from natural solubilization of $F$ from high fluoride volcanic rocks associated with the Rift Valley [5].

Technologies for removal of fluoride from water include precipitation, distillation, ion exchange, membrane technologies, reverse osmosis, and electro dialysis [6]. Application of these methods is however limited by high costs of operation, high energy and technical skill requirements and inefficiencies of some of them particularly at low F contamination levels [7]. Adsorption utilizing natural and inexpensive adsorbents and other modified materials which are adaptable to local needs would be ideal alternative. Various low cost materials including activated carbons, alumina, silica, some bio-sorbents and a number of natural and synthetic resins have previously been investigated for F adsorption [8-12]. Activated carbons, silica and alumina are however, expensive and require frequent regeneration to maintain their efficiency. Many synthetic resins on the other hand, are non-biodegradable raising environmental concerns whereas biosorbents are prone to chemical and biological attack which reduces their efficacy. Apparently, clays and similar soil materials are most plausible alternative adsorbents because they are robust, readily available in stable and safe forms and present attractive natural adsorptive properties for various solutes [13]. 
The diatomaceous earth used in this work, and similar mineral adsorbents, for instance, are well known for their adsorptive properties. The mineral is obtainable from a mining site located in areas reported for high $F$ waters [5] which makes it an ideal starting material in search of a water defluoridant. It was ground and treated with excess $\mathrm{HCl}$ before it was assessed for $\mathrm{F}$ removal from aqueous solutions. The effect of $\mathrm{pH}, \mathrm{F}$ concentration, and time of contact, adsorbent dosage and temperature was studied and Freundlich and Langmuir isotherms used to validate the adsorption equilibrium.

\section{Experimental}

\subsection{Preparation of the Materials}

The adsorbent material was collected from natural deposits at Kariandusi in Gilgil District, Nakuru County, Kenya. It was air dried and crushed to pass through $<2$ $\mathrm{mm}$ mesh. Ten-gram portions of ground samples were soaked in $100 \mathrm{~mL}$ of $0.1 \mathrm{M} \mathrm{HCl}$ and the mixture magnetically agitated for varying length of time between 0 and 420 minutes. At the end of the shaking period, each of the samples was suction filtered, washed with excess deionized water and dried at $383 \mathrm{~K}$ overnight before being assessed for $\mathrm{F}$ uptake. The fluoride adsorption tests were carried out using initial $\mathrm{F}$ concentration of 1000 $\mathrm{mg} / \mathrm{L}$, at $293 \mathrm{~K}$, and adsorbent dosage of $0.1 \mathrm{~g} / \mathrm{mL}$. The samples with highest $F$ adsorption efficiency were designated Acid Treated Diatomaceous Earth (ATDE) and employed in the rest of the tests. The F adsorption efficiency of ATDE was then compared with that of untreated samples.

\subsection{Characterization of the Adsorbent Materials}

The pH of ATDE was measured using a Hanna Instruments $\mathrm{pH}-211$-microprocessor $\mathrm{pH}$ meter in $1 \mathrm{M} \mathrm{KCl}$ by 24-hour soaking of $5 \mathrm{~g}$ of ATDE in $50 \mathrm{~mL}$ aliquots of the salt solution and the zero point of charge, pHznc, by fast alkalimetric titration [14]. Chemical analysis was determined using a Varian Atomic Absorption Spectrophotometer (AAS) model spectr AA and loss on ignition (LOI) determined by ashing known mass (g) of the sample at 1273 K. X-ray diffraction analysis which was employed in mineralogical analysis of the adsorbent was carried out on a P-Analytical X' pert PRO PW-3040/60 diffractommeter with $\mathrm{Cu} \mathrm{K} \alpha$ radiation at a scan speed of $1.2^{\circ}$ $\min ^{-1}$ over a range of $5^{\circ}$ to $70^{\circ}$. Analytical grade reagents were used throughout the tests.

\subsection{Adsorption Experiments}

All adsorption tests unless otherwise specified, were carried out on batch basis at room temperature (298 $\pm 0.5 \mathrm{~K})$ as follows: known amounts of ATDE were placed in a
$100 \mathrm{~mL}$ stopperred Erlenmeyer flasks containing $50 \mathrm{~mL}$ of $\mathrm{F}$ ions solution of a known concentration and shaken for a given time length. The solutions were centrifuged and $\mathrm{F}$ concentration in the supernatant measured using a Tx EDT Model 3221 direct-ion electrode. The amount of $\mathrm{F}$ adsorbed, $q_{e}(\mathrm{mg} / \mathrm{g})$, was calculated from the expression:

$$
q_{e}=\left(C_{e}-C_{i}\right) \frac{V}{m}
$$

whereas, the percentage $\mathrm{F}$ adsorption from the relationship:

$$
\frac{\left(C_{e}-C_{i}\right)}{C_{i}} \times 100
$$

where, $C_{i}$ and $C_{e}$ are initial and final equilibrium $\mathrm{F}$ concentrations $(\mathrm{mg} / \mathrm{L})$ respectively, $V(\mathrm{~mL})$ is the volume and $m(\mathrm{~g})$ is the mass of ATDE used.

\section{Results and Discussion}

\subsection{Effect of Acid Treatment}

Effect of acid-treatment of Diatomaceous Earth (DE) whose major characteristics are presented in Table 1 was examined by batch adsorption tests using $1000 \mathrm{mg} / \mathrm{L}$ initial $\mathrm{F}$ concentration, $0.1 \mathrm{~g} / \mathrm{mL}$ adsorbent dosage ratio at $293 \mathrm{~K}$ for different time intervals of mineral exposure to $0.1 \mathrm{M} \mathrm{HCl}$. The results of these tests are presented in Figure 1.

Table 1. Summary of main characteristics of ATDE.

\begin{tabular}{cc}
\hline Property & Value (\%) \\
\hline $\mathrm{SiO}_{2}$ & $70.40 \%$ \\
$\mathrm{Al}_{2} \mathrm{O}_{3}$ & $9.29 \%$ \\
$\mathrm{Fe}_{2} \mathrm{O}_{3}$ & $3.76 \%$ \\
$\mathrm{~K}_{2} \mathrm{O}$ & $2.36 \%$ \\
$\mathrm{Na}_{2} \mathrm{O}$ & $1.00 \%$ \\
$\mathrm{Fe}_{2} \mathrm{O}_{3}$ & $1.00 \%$ \\
$\mathrm{CaO}$ & $0.77 \%$ \\
$\mathrm{MgO}^{2}$ & $0.33 \%$ \\
$\mathrm{TiO}_{2}$ & $0.61 \%$ \\
$\mathrm{MnO}$ & $0.08 \%$ \\
$\mathrm{LOI}$ & $11.88 \%$ \\
$\mathrm{pH}$ & $3.4 \pm 0.2$ \\
$\mathrm{PHznc}$ & $3.8 \pm 0.2$ \\
& \\
Quartz, HP & $\mathrm{SiO}_{2}$ \\
Montmorillonite-22A & $\mathrm{Na}_{0.3}\left(\mathrm{Al}, \mathrm{Mg}_{2} \mathrm{Si}_{4} \mathrm{O}_{10}(\mathrm{OH})_{2.8} \mathrm{H}_{2} \mathrm{O}\right.$ \\
\hline
\end{tabular}




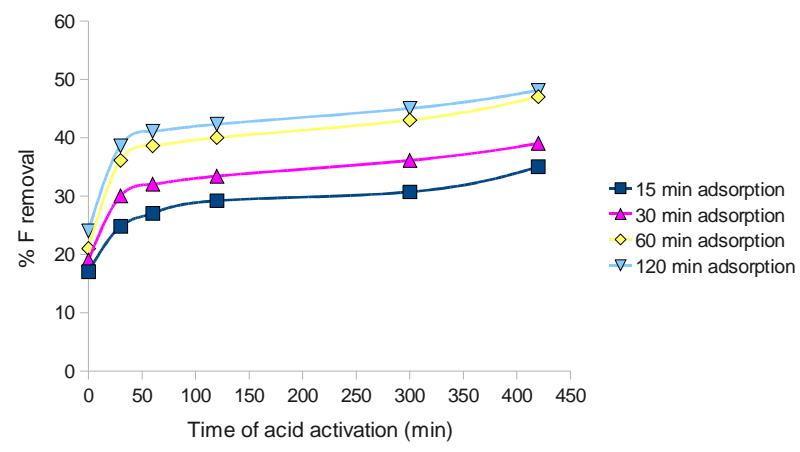

Figure 1. Effect of time of acid activation on $F$ adsorption onto ATDE from $1000 \mathrm{mg} / \mathrm{L}$ solution at $293 \mathrm{~K}$ using 0.1 $\mathrm{g} / \mathrm{mL}$ adsorbent dosage in a batch system.

The $\mathrm{F}$ adsorption capacity of the mineral rapidly increased with increasing time of contact with the acid from just about $24 \%$ for untreated samples (time zero) to about $40 \%$ for 60 minutes acid treated materials. Thereafter, the increase in F uptake was marginal; barely reaching 50\% for 420-min acid-treated samples. The 60-min contact of the mineral with the acid was sufficient to activate the mineral for $\mathrm{F}$ adsorption.

The $\mathrm{pH}$ and the pHznc of the 60 -min acid treated material which was then designated as acid treated diatomaceous earth, ATDE, were determined and the results included in Table 1. As expected, the pH of ATDE was lower than the pHznc indicating that as a result of acid treatment, the mineral surface had developed a net positive surface charge requisite for anionic adsorption. This indicates that on contacting the adsorbent with the acid, $\mathrm{H}^{+}$ions rapidly adsorbed on to the mineral surface increasing the surface potential for adsorption of $\mathrm{F}$ ions. The ATDE surface was strongly enhanced for F uptake by treatment in dilute $\mathrm{HCl}$. Alternative activation protocol could however be exploited to further improve the performance of the adsorbent.

\subsection{Effect of Adsorbent Dosage}

The amount of contact surface between an adsorbent and adsorbate solution plays an important role in adsorption process. The effect of varying adsorbent mass while maintaining the adsorbate volume and concentration constant was studied as follows: 15, 20, 25, 30 and 35-gram portions of the adsorbent were placed in $50 \mathrm{~mL}$ aliquots of the adsorbate solution containing $1000 \mathrm{mg} / \mathrm{L}$ of $\mathrm{F}$ and agitated on a DKZ model 1 shaking water-bath at $293 \mathrm{~K}$ for $20 \mathrm{~min}$. The percentage $\mathrm{F}$ removal was determined and plotted against the mass of the adsorbent and the results presented in Figure 2.

The overall percentage $\mathrm{F}$ removal from solution rapidly increased with increase in ATDE dosage. More than $90 \% \mathrm{~F}$ adsorption could be achieved at 30 g per 50
mL ATDE batch dosage. Adsorbent doses greater than $35 \mathrm{~g}$ per $50 \mathrm{~mL}$ of solution were however, not possible because the slurry became too thick to agitate effectively. This rise in F removal efficiency with increasing adsorbent dosage was ascribed to increased availability of adsorptive surface in the solution [15]. The adsorbent dosage ratio of $0.5 \mathrm{~g} / \mathrm{mL}$ was adequate for $80 \% \mathrm{~F}$ adsorption. These ratios were therefore adopted in the rest of the tests.

\subsection{Effect of Temperature}

Batch experiments were carried out using $1000 \mathrm{mg} / \mathrm{L} \mathrm{F}$ solutions at selected temperatures between 293 and 323 $\mathrm{K}$ by agitating the adsorption mixture for $60 \mathrm{~min}$ and the results presented in Figure 3.

The percentage $\mathrm{F}$ uptake increased sharply with increasing temperature from just about $40 \%$ at $293 \mathrm{~K}$ to $92 \%$ at $303 \mathrm{~K}$ before the system gradually approached the equilibrium with $100 \% \mathrm{~F}$ removal at $313 \mathrm{~K}$. It can be assumed that increase in temperature strongly increased the energy of the ions. More F ions could therefore interact effectively with the surface groups in ATDE for adsorption to occur resulting in higher percentage $\mathrm{F}$ removal from solution. The most efficient temperatures were therefore within the ambient daytime tropical tem-

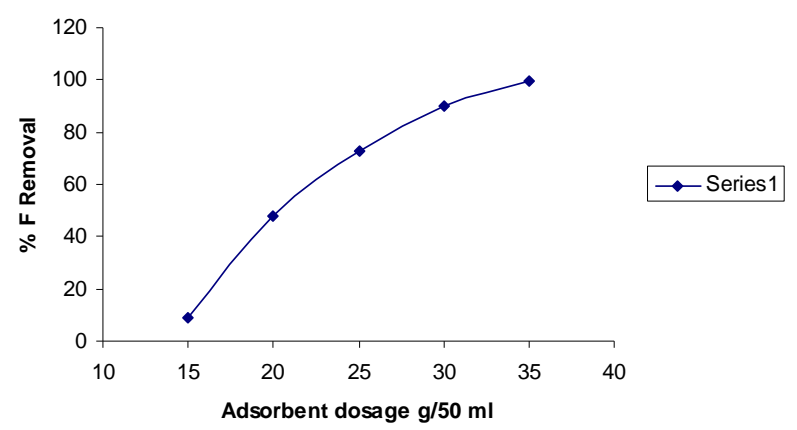

Figure 2. Effect of adsorbent dosage using $50 \mathrm{~mL}$ of the adsorbate solution containing $1000 \mathrm{mg} / \mathrm{L}$ of $\mathrm{F}$ being shaken for $20 \mathrm{~min}$ at $293 \mathrm{~K}$.

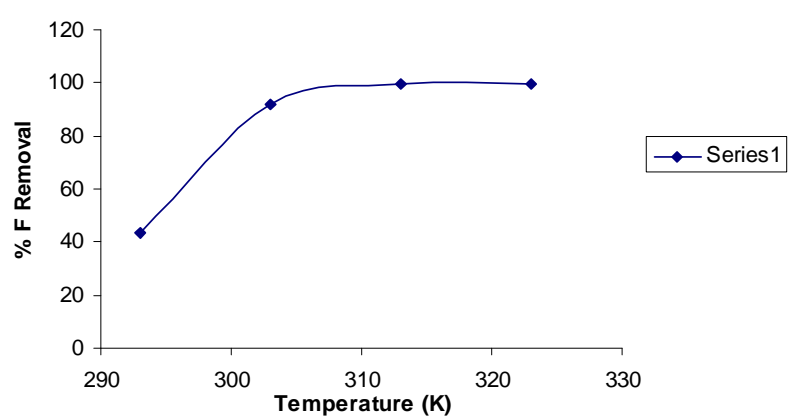

Figure 3. Effect of temperature studied at $\mathbf{p H} 3.4$ using 0.5 $\mathrm{g} / \mathrm{mL}$ adsorbent dosage and $1000 \mathrm{mg} / \mathrm{L}$ initial fluoride concentration. 
peratures (298 - $313 \mathrm{~K}$ ) showing that F ions could, effecttively, be removed from solutions using these materials without prior temperature adjustments. The process was however reverseble at lower temperatures indicating that the adsorption of fluoride on ATDE was endothermic.

\subsection{Effect of Initial Adsorbate $\mathrm{pH}$ and Time of Contact}

The time-dependent F adsorption onto ATDE was studied by varying equilibration time from 0 to $80 \mathrm{~min}$ using initial F concentration of $1000 \mathrm{mg} / \mathrm{L}$. The adsorption studies were carried out under constant agitation on a DKZ model 1 shaking water bath at $303 \mathrm{~K}$ and initial $\mathrm{pH}$ values of 1.56, 3.32, 5.24 and 6.89 respectively. The $\mathrm{pH}$ adjustments were achieved by addition of small amounts of $1 \mathrm{M} \mathrm{NaOH}$ or $1 \mathrm{M} \mathrm{HCl}$ using $50 \mu \mathrm{L}$ burettes. The percentage $\mathrm{F}$ adsorption was plotted against contact time and the results presented in Figure 4.

As it can be seen from Figure 4, 98.8\% F adsorption could be attained in just $10 \mathrm{~min}$ at initial $\mathrm{pH}$ of 3.32. The initial rapid $\mathrm{F}$ adsorption then gave way to a very slow process and gradual increase in percentage $\mathrm{F}$ uptake could still be observed at $80 \mathrm{~min}$. This also meant that, the equilibrium removal of fluoride increased with increasing $\mathrm{pH}$ to a pick of $98.8 \%$ at 3.32 and decreased there on as it has also been reported for similar adsorbents in the literature [9]. The observed lower $\mathrm{F}$ adsorption at very low $\mathrm{pH}$ values could be ascribed to competition for sorptive sites by $\mathrm{Cl}^{-}$ions from $\mathrm{HCl}$ in solution and to the collapse of the crystalline chemical structure of the adsorbent under strong acidic conditions. However, the $\mathrm{F}$ adsorption changed only insignificantly from about $98.8 \%$ to just below $98.0 \%$ when the solution $\mathrm{pH}$ was raised from 1.56 to 6.89 . It was evident that, although $\mathrm{F}$ adsorption on ATDE was somehow favored by strongly acidic $\mathrm{pH}$ values of about 3.32 , change in the solution $\mathrm{pH}$ did not affect the adsorption of F onto ATDE strongly. This shows that the F ions has got such strong

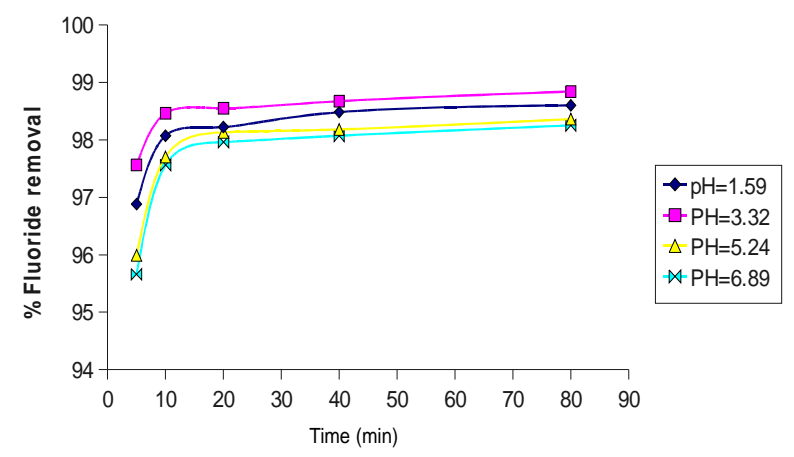

Figure 4. Effect of initial adsorbate $\mathrm{pH}$ and time of contact using $1000 \mathrm{mg} / \mathrm{L} \mathrm{F}$ solution at $303 \mathrm{~K}$ and $0.5 \mathrm{~g} / \mathrm{mL} \mathrm{ATDE}$ batch dosage. affinity for ATDE surface that it could approach and adsorb into the adsorbent material against strong coulombic repulsions from adsorbed surface $\mathrm{OH}^{-}$ions at high $\mathrm{pH}$ values. This means that ATDE could be used to defluoridate aqueous systems at neutral $\mathrm{pH}$ values of most water solutions without need for prior $\mathrm{pH}$ adjustments.

\subsection{Effect of Dissolved Competing Ions}

Because of the apparent indifference of $\mathrm{F}$ adsorption to $\mathrm{pH}$ changes and hence to the concentration of $\mathrm{OH}^{-}$ions discussed in sections 3.4, the influence of potential competing anions was studied using $1000 \mathrm{mg} / \mathrm{L} \mathrm{F}$ adsorbate solutions in $0.1 \mathrm{M}$ background solutions containing respective competing anions as potassium salts. The results for these tests are presented in Figure 5.

As expected, apart from the chloride, the oxo-anions appeared to have no obvious influence on $\mathrm{F}$ adsorption. The $\mathrm{F}$ ions were able to adsorb preferentially at ATDE surfaces in presence of the other anions. It can be assumed that the chloride having a smaller spatial radius and less steric hindrance than the oxo-anions, had higher mobility and penetration in solution and therefore competed more effectively with $\mathrm{F}$ for adsorptive sites in ATDE thereby reducing $F$ adsorption more strongly. However, the preferential uptake of the $\mathrm{F}$ ion shows that $\mathrm{F}$ ions were able to penetrate and adsorb to inner sites in ATDE which were inaccessible to the other ions. This shows that the adsorption of F onto ATDE is not affected by these ions. The F ions can therefore selectively be removed from solution in presence of the nitrates, sulphates and phosphates using this defluoridation protocol.

\subsection{Equilibrium Analysis}

Equilibrium experiments are useful in elucidating adsorption mechanism, characterization of adsorbates, assessment of adsorbent surfaces and they can provide useful insight in the dynamics of the adsorption process [16]. For equilibrium tests of F uptake by ATDE, 25-gram

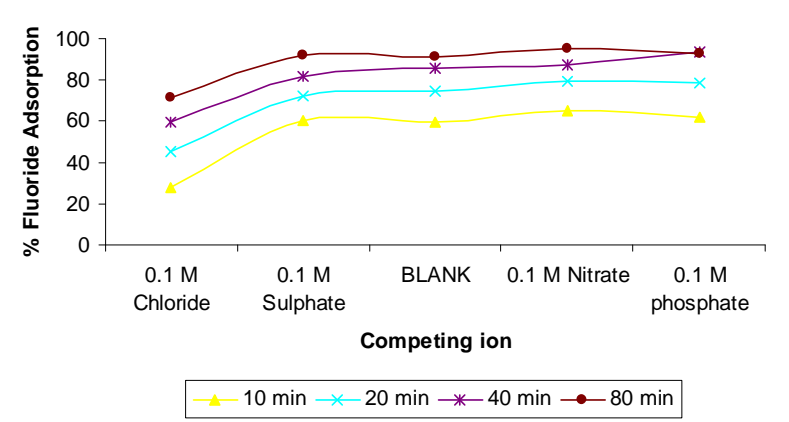

Figure 5. Effect of dissolved competing ions using 1000 $\mathrm{mg} / \mathrm{L} \mathrm{F}$ adsorbate solutions prepared in $0.1 \mathrm{M}$ background solutions containing respective competing anions as potassium salts at $0.5 \mathrm{~g} / \mathrm{mL}$ adsorbent dosage, $303 \mathrm{~K}$ and $\mathrm{pH} 3.4$. 
portions of ATDE were agitated for $20 \mathrm{~min}$ in $50 \mathrm{~mL}$ aliquots of adsorbate solution containing between 5 and $1000 \mathrm{mg} / \mathrm{L} \mathrm{F}$ ions at a pH of $3.4 \pm 0.2$ and $303 \mathrm{~K}$. The tests were repeated at $313 \mathrm{~K}$ for comparison and the results presented in Figure 6.

Complete removal of Fluoride ions was recorded up to $200 \mathrm{mg} / \mathrm{L}$ initial $\mathrm{F}$ concentration at $303 \mathrm{~K}$ and up to 400 $\mathrm{mg} / \mathrm{L}$ for $313 \mathrm{~K}$ respectively. The percentage $\mathrm{F}$ removal thereafter declined sharply at both temperatures due to rapid saturation of adsorptive sites in the adsorbent. Within the concentration range used in this work, the percentage $\mathrm{F}$ adsorption at $303 \mathrm{~K}$, leveled off at $400 \mathrm{mg} / \mathrm{L}$. However, even at $1000 \mathrm{mg} / \mathrm{L}$ initial F concentration, the F removal efficiency of ATDE at $313 \mathrm{~K}$ was still reducing. It was evident, therefore, that ATDE is a highly porous material with high anion exchange capacity and the adsorption capacity of the material is highly temperature dependent. The results showed that ATDE could effectively be utilized in defluoridation of aqueous solutions in the $\mathrm{F}$ contamination range of natural waters at ambient tropical temperatures which approximates those used in this study (303 K).

An adsorption isotherm was constructed by plotting the amount of adsorbed $\mathrm{F}, q_{e}(\mathrm{mg} / \mathrm{g})$, versus the equilibrium concentration, $C_{e}(\mathrm{mg} / \mathrm{L})$, and the results presented in Figure 7.

Fluoride adsorption increased with increasing initial concentration. It can be assumed that higher initial fluoride concentration enhanced the anion exchange potential of the adsorbate and resulted in higher adsorption capacity [17]. Based on the initial part of the curve being vertical to the concentration axis, the Fluoride adsorption isotherm could be classified as an $\mathrm{H}$ type isotherm according to Giles classification of adsorption isotherms. This showed that ATDE has got such high affinity for F that at low concentrations the $\mathrm{F}$ ion were completely adsorbed. This implies that ion-exchange mechanisms involving solutes of lower affinities for ATDE surfaces could be the

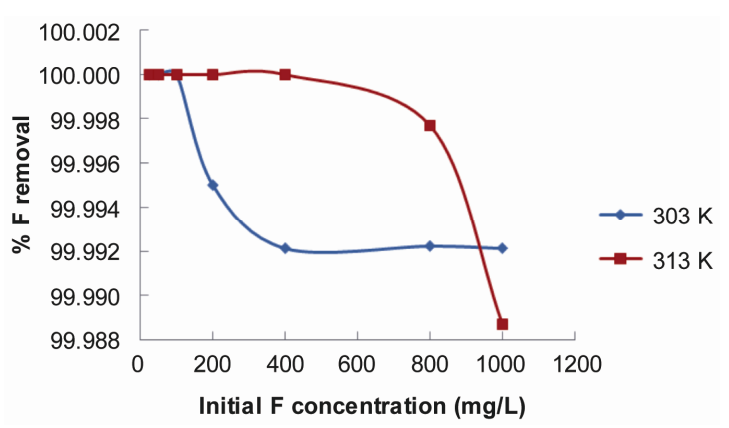

Figure 6. Effect of change in the initial fluoride concentration on its uptake by ATDE using 25 gram per $50 \mathrm{~mL}$ ATDE batch dosage agitated for $20 \mathrm{~min}$ at $\mathrm{pH} 3.4$ and 303 $\mathrm{K}$ and at $313 \mathrm{~K}$ temperature respectively. main process in $\mathrm{F}$ adsorption onto ATDE. It shows that $\mathrm{F}$ adsorption onto ATDE could therefore be chemical in nature involving stoichiometric inner-sphere complexation with ATDE surface groups. This is consistent with earlier postulates in Section 3.4 and 3.5 that electronic and geometrical attributes of the $\mathrm{F}$ appear to favor its preferential adsorption onto ATDE solutes.

The linear Langmuir and Freundlich models were plotted for the $\mathrm{F}$ adsorption data and their respective isothermal constants calculated. The Langmuir isotherm was used in the form:

$$
\frac{1}{q_{e q}}=\frac{1}{b q_{\max } C_{e q}}+\frac{1}{q_{\max }}
$$

where $C_{e}$ is the equilibrium concentration (mg/L), $q_{e}$ the amount of metal ion adsorbed (mg/g), $q_{\max }$ is the $q_{e}$ for a complete monolayer coverage of the material by the adsorbate $(\mathrm{mg} / \mathrm{g})$, and $b$ sorption equilibrium constant (L/ $\mathrm{mg}$ ). The equation assumes that adsorption takes place at specific energetically homogeneous sites within the adsorbent. It is then assumed that once an adsorbate ion occupies a site, no further adsorption can take place at that site. The rate of adsorption to the surface should then be proportional to the adsorbate concentration in solution and the available area of free sites. The Langmuir isothermal plot and the corresponding constants are given in Figure 8 and Table 2 respectively.

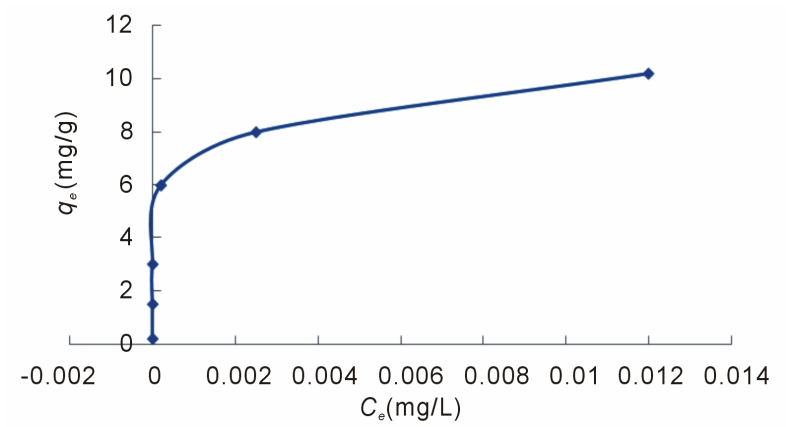

Figure 7. A general equilibrium isotherm for fluoride adsorption onto ATDE.

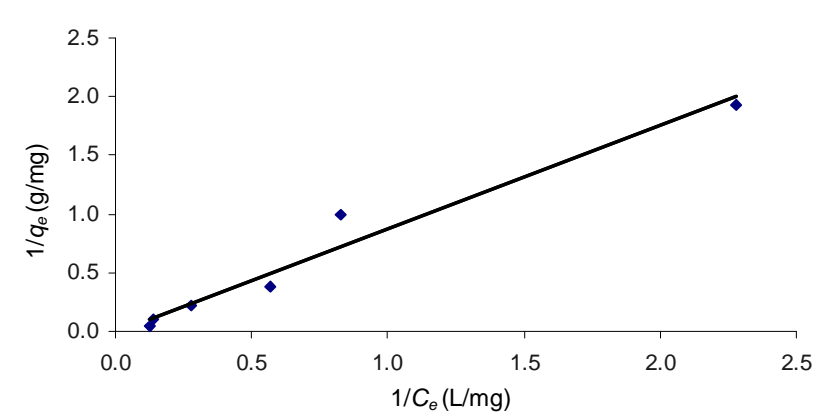

Figure 8. Langmuir adsorption isotherm for fluoride adsorption on to ATDE. 
Table 2. Langmuir and Freundlich adsorption constants compared with those of selected low-cost fluoride adsorbents in literature.

\begin{tabular}{ccccccc}
\hline \multirow{2}{*}{ Adsorbent } & \multicolumn{3}{c}{ Langmuir isotherm } & \multicolumn{3}{c}{ Freundlich isotherm } \\
\cline { 2 - 7 } & $\boldsymbol{q}_{\max }(\mathbf{m g} / \mathbf{g})$ & $\boldsymbol{b}$ (L/mg) & $\boldsymbol{R}^{2}$ & $\boldsymbol{K}_{f}$ & $\boldsymbol{n}$ & $\boldsymbol{R}^{2}$ \\
\hline ATDE (in this work) & 51.81 & 0.0223 & 0.9692 & 1.185 & 0.6524 & 0.9345 \\
Alumimium sulphate [18] & 1.7142 & 0.3744 & - & 1107.67 & -1.8447 & - \\
Montmorillonite clay [19] & 1.485 & 4.202 & 0.995 & 0.279 & 2.551 & 0.829 \\
Attapulgite [17] & 40.09 & 0.00804 & 0.997 & 0.776 & 1.4728 & 0.994 \\
An Activated carbon [11] & 4.617 & 1.58 & 0.9990 & 3.024 & 5.0251 & 0.994 \\
\hline
\end{tabular}

The linearized Freundlich isotherm was adopted as:

$$
\log q_{e q}=\log K_{f}+n \log C_{e q}
$$

where, $n$ is a constant characteristic of the intensity of surface loading of the adsorbate on the adsorbent and $K_{f}$ is a constant indicative of the affinity of the adsorbent for the adsorbate particles. Adherence of adsorption data to the Freundlich isotherm postulates that adsorption proceeds by completely reversible multilayer physisorption based on weak van der Waals type of interactions between adsorbent and adsorbate particles. The isotherm does not predict surface saturation by the adsorbate. Therefore, the surface covering is mathematically unlimited. The Freundlich plot and calculated isothermal constants values are given in Figure 9 and in Table 2 respectively.

As can be seen from the respective figures, the Langmuir and Freundlich isotherms fitted the adsorption data with $R^{2}$ values of 0.97 and 0.93 respectively. This shows that the adsorption process could be described by these models although the data fit for the Langmuir isotherm was somehow better. Similar findings have been reported for heat treated diatomite [20]. The affinity coefficient $K_{f}$ and intensity parameter $n$ values of the Freundlich isotherm indicate effective binding of adsorbate particles by the material. More so, as can be seen, the value of $n$ was less than unity, which indicates that the adsorption proc-

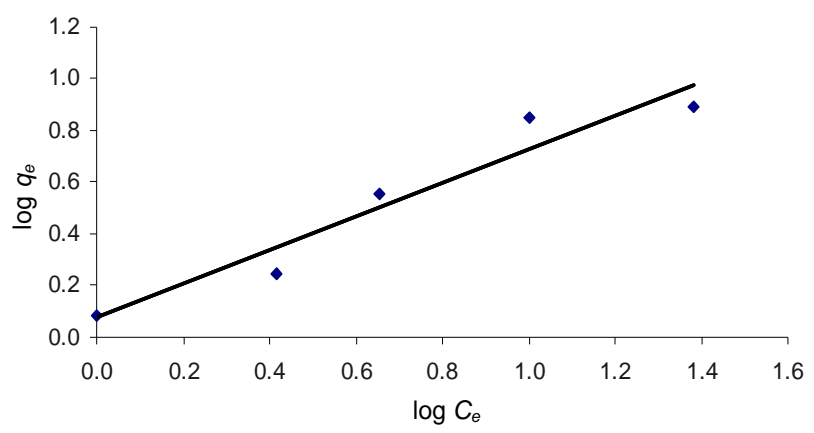

Figure 9. Freundlich isotherm for the fluoride adsorption on to ATDE. ess is not entirely monolayer in coverage. This means that the mineral surface does not have completely homogeneous surfaces as can be seen from mineralogical analysis in Section 3.1.

The comparison of Langmuir and Freundlich isothermal constant with those of other low-cost adsorbents given in Table 2 show that, ATDE has superior adsorption characteristic compared to those of the other lowcost adsorbents as it had higher adsorption capacity than any of the other low adsorbents, the corresponding Freundlich affinity constant $K_{f}$ was quite high and the Freundlich intensity constant was between 0 and 1 signifying effective sorption of $\mathrm{F}$ by the adsorbent. In general it can be concluded that acid treated diatomaceous mineral, ATDE, from a mining site in Kenya has got robust adsorption properties and could efficiently be utilized as inexpensive and safe adsorbent for the removal of $F$ from aqueous systems.

\section{Conclusions}

From the results in this work, it was found that a diatomaceous mineral from Kariandusi mining site in Kenya could greatly be enhanced for $\mathrm{F}$ adsorption by simple pretreatment in dilute $\mathrm{HCl}$. Because of high affinity of the acid pretreated mineral for $\mathrm{F}$ ions, the $\mathrm{pH}$ and the presence of other competing ions could not affect the $\mathrm{F}$ adsorption onto its surface. The F ions could adsorb equally well on to the mineral surfaces even in high concentrations of other negatively charged ions. The temperature was the main variable affecting $F$ uptake onto ATDE. The adsorption process was favored by elevated temperatures range of 303 - $313 \mathrm{~K}$. It was therefore suggested that $\mathrm{F}$ adsorption onto ATDE was spontaneous and endothermic. The equilibrium isotherm for the process could be classified as $\mathrm{H}$ Type following Giles classification of isotherms; which attests to the high affinity between $\mathrm{F}$ and the adsorbent surface. With a high Langmuir adsorption capacity of $51.1 \mathrm{mg} / \mathrm{g}$, this study has demonstrated that ATDE, a naturally occurring mineral 
abundantly and cheaply obtainable from a mining site in Kenya could be used as a plausible, cheap and safe F adsorbent for defluoridating fluoride polluted aqueous streams.

\section{Acknowledgements}

This study was funded jointly by the International Foundation for Science (IFS) and the Kenya National Council for Science and Technology (NCST).

\section{REFERENCES}

[1] World Health Organization, "WHO Chemical fact sheets: Fluoride,” Vol. 1, 3rd Edition, WHO, Geneva, 2006, pp. 375-377.

[2] G. L. Waldbott, "Systematic Poisons: Fluoride and Cadmium,” In: G. L. Waldbott, Ed., Health Effects of Environmental Pollutants, 2nd Edition, C. V. Mosby Company, St. Louis, 1978, pp. 150-168.

[3] A. A. Yates, S. A. Schlicker and C. W. Suitor, "Food and Nutrition Board, Institute of Medicine, National Academy of Sciences. Dietary Reference Intakes: The New Basis for Recommendations for Calcium and Related Nutrients, B Vitamins, and Choline," Journal of American Dietetic Association, Vol. 98, No. 6, 1998, pp. 699-706. doi:10.1016/S0002-8223(98)00160-6

[4] C. Reimann, K. Bjorvatn, B. Frengstad, Z. Melaku, R. T. Haimanot and U. Siewers, "Drinking Water Quality in the Ethiopian Section of the East African Rift Valley I-Data and Health Aspects," The Science of the Total Environment, Vol. 311, No. 1-3, 2003, pp. 65-80. doi:10.1016/S0048-9697(03)00137-2

[5] E. W. Wambu and G. K. Muthakia, "High Fluoride Water in the Gilgil Area of Nakuru County, Kenya,” Fluoride, Vol. 44, No. 1, 2011, pp. 37-41.

[6] S. K. Nath and R. K. Dutta, "Fluoride Removal from Water Using Crushed Limestone,” Indian Journal of Chemical Technology, Vol. 17, 2010, pp. 120-125.

[7] S. A. Esmaili, A. S. Nasseri, A. R. Mahvi and R. AtashDehghan, "Adsorption of Lead and Zinc Ions from Aqueous Solution by Volcanic Ash Soil,” 2003. http://www.x-cd.com/sudbury03/prof41.html

[8] Y. Vijaya and A. Krishnaiah, "Sorptive Response Profile of Chitosan Coated Silica in the Defluoridation of Aqueous Solution,” E-Journal of Chemistry, Vol. 6, No. 3, 2009, pp. 713-724.

[9] G. Karthikeyan, A. Shanmuga Sundarraj, S. Meenakshi and K. P. Elango, “Adsorption Dynamics and the Effect of Temperature of Fluoride at Alumina Solution Interface," Journal of the Indian Chemical Society, Vol. 81, No.
6, 2004, pp. 461-466.

[10] Y. Ku and H. Chiou, "The Adsorption of Fluoride Ion from Aqueous Solution by Activated Alumina," Water, Air and Soil Pollution, Vol. 133, No. 1-4, 2002, pp. 249361.

[11] G. Alagumuthu, V. Veeraputhiran and R. Venkataraman, "Fluoride Sorption Using Cynodon dactylon-Based Activated Carbon,” Hemijska Industrija, Vol. 65, No. 1, 2011, pp. 23-35. doi:10.2298/HEMIND100712052A

[12] A. V. Jamode, V. S. Sapkal, V. S. Jamode and S. K. Deshmukh, "Adsorption Kinetics of Defluoridation Using Low-Cost Adsorbents," Adsorption Science \& Technology, Vol. 22, No. 1, 2009, pp. 65-73. doi:10.1260/026361704323151006

[13] M. Karthikeyan, V. Gopal and K. P. Elango, “Adsorption of Fluoride Ions onto Naturally Occurring Earth Materials,” Journal of Applied Sciences and Environmental Management, Vol. 14, No. 4, 2010, pp. 90-95.

[14] C. H. Weng, C. Z. Tsai, S. H. Chu and Y. C. Sharma, "Adsorption Characteristics of Copper (II) onto Spent Activated Clay,” Separation and Purification Technology, Vol. 54, No. 2, 2007, pp. 187-197. doi:10.1016/j.seppur.2006.09.009

[15] S. Ho, D. A. J. Wase and C. F. Forster, "Batch Nickel Removal from Aqueous Solution by Sphagnum Moss Peaty,” Water Research, Vol. 29, No. 5, 1995, pp. 13271332. doi:10.1016/0043-1354(94)00236-Z

[16] E. W. Wambu, G. K. Muthakia, J. K. Wa-Thiong’o and P. M. Shiundu, "Kinetics and Thermodynamics of Aqueous $\mathrm{Cu}(\mathrm{II})$ Adsorption on Heat Regenerated Spent Bleaching Earth,” Bulletin of the Chemical Society of Ethiopia, Vol. 25, No. 2, 2011, pp. 1-10.

[17] J. Zhang, S. Xie and Y. S. Ho, "Removal of Fluoride Ions from Aqueous Solution Using Modified Attapulgite as Adsorbent," Journal of Hazardous Materials, Vol. 165, No. 1-3, 2009, pp. 218-222. doi:10.1016/j.jhazmat.2008.09.098

[18] R. N. Yadav, O. P. Singh and R. Yadav, "Study of the Aluminum Ammonium Sulphate as Defluoridated Agent in Drinking Water Earthenware," Archives of Applied Science Research, Vol. 2, No. 3, 2010, pp. 11-22.

[19] G. Karthikeyan, A. Pius and G. Alagumuthu, "Fluoride Adsorption Studies of Montmorillonite Clay," Indian Journal of Chemical Technology, Vol. 12, No. 3, 2005, pp. 263-272.

[20] S. Janta, S. Watanesk, R. Watanesk and S. Thiansem, "Cost Effective Natural Adsorbent for Fluoride Re- moval,” Advanced Material Research, Vol. 55-57, 2008, pp. 865-868 doi:10.4028/www.scientific.net/AMR.55-57.865 